\title{
A transplantable human medullary thyroid carcinoma as a model for RET tyrosine kinase-driven tumorigenesis
}

\author{
Viktor Johanson 1,2, Håkan Ahlman ${ }^{1,2}$, Peter Bernhardt ${ }^{4}$, Svante Jansson ${ }^{1,2}$, \\ Lars Kölby ${ }^{1,2}$, Fredrik Persson 1,3 , Göran Stenman ${ }^{1,3},{ }^{1,3}$ Christina Swärd ${ }^{1,2}$, \\ Bo Wängberg ${ }^{1,2}$, Mats Stridsberg ${ }^{5}$ and Ola Nilsson ${ }^{1,3}$
}

\footnotetext{
${ }^{1}$ Lundberg Laboratory for Cancer Research, Sahlgrenska University Hospital, SE-413 45 Göteborg, Sweden

${ }^{2}$ Department of Surgery, Sahlgrenska University Hospital, SE-413 45 Göteborg, Sweden

${ }^{3}$ Department of Pathology, Sahlgrenska University Hospital, SE-413 45 Göteborg, Sweden

${ }^{4}$ Department of Radiation Physics, Sahlgrenska University Hospital, SE-413 45 Göteborg, Sweden

${ }^{5}$ Department of Medical Sciences, Uppsala University Hospital, Uppsala, Sweden

(Requests for offprints should be addressed to V Johanson; Email: viktor.johanson@medfak.gu.se)
}

\begin{abstract}
Hereditary medullary thyroid carcinoma (MTC) is caused by germline mutations in the RET protooncogene, resulting in constitutive activation of the RET tyrosine kinase. A substantial proportion of sporadic MTCs also have RET mutations, making the RET tyrosine kinase a potential therapeutic target in MTC. We have established a transplantable MTC in nude mice from a sporadic human MTC carrying a RET C634R mutation. Transplanted tumors had an exponential growth rate with an approximate doubling time of about 3 weeks, and expressed a neuroendocrine phenotype characteristic of MTC, e.g., expression of calcitonin, chromogranin A ( $\mathrm{ggA})$, synaptophysin, synaptic vesicle protein 2 (SV2), vesicular monoamine transporter-1 and -2 , carcinoembryonic antigen, cytokeratin $8 / 18$, epithelial cadherin, and neural cell adhesion molecule. Plasma calcitonin and $\mathrm{CgA}$ levels were elevated in tumor-bearing mice and correlated with tumor size. Cytogenetic analysis, including spectral karyotyping, confirmed the human origin of the xenografted tumors and demonstrated an abnormal, near triploid karyotype. Treatment of tumor-bearing nude mice with the tyrosine kinase inhibitor ZD6474, which specifically inhibits RET, epidermal growth factor receptor (EGFR), and vascular endothelium growth factor receptor (VEGFR) tyrosine kinases, resulted in a dose-dependent inhibition of tumor growth. Oral ZD6474 given once daily ( $250 \mathrm{mg} / \mathrm{kg}, 5$ days $/$ week) reduced tumor volume to $11 \%$ when compared with controls after 4 weeks. Our results show that this transplantable MTC, designated GOT2, represents a novel and useful model for studies of MTC and RET tyrosine kinase-dependent tumor growth.
\end{abstract}

Endocrine-Related Cancer (2007) 14 433-444

\section{Introduction}

Medullary thyroid carcinoma (MTC) accounts for 5$10 \%$ of all thyroid cancer. Most cases are sporadic but about 25\% occur in patients with the multiple endocrine neoplasia type 2 (MEN2) syndrome (Brauckhoff et al. 2004). Most patients with sporadic MTC present with metastatic disease. In these patients, curative surgery can be performed in less than half of the cases (Moley et al. 1998). Since MTC originates from the C-cells of the thyroid, this tumor type lacks the iodine pump and cannot be treated with radioiodine. MTC is neither very sensitive to external radiation (Samaan et al. 1992) nor to chemotherapy (Wu et al. 1994). The best response rate (15\%) has been obtained with drugs used for other neuroendocrine tumors (Schlumberger et al. 1995). In addition, radioimmunotherapy with radionuclides coupled to anti-carcinoembryonic antigen (CEA) antibodies has been attempted (Juweid et al. 1996). Novel systemic treatment strategies are clearly needed for these patients.

Hereditary MTCs and a substantial proportion of sporadic MTCs harbor activating mutations in the RET tyrosine kinase (Eng 1999). In MEN2A, mutations in 
$R E T$ are clustered in the region coding for the cysteinerich, extracellular domain of the receptor, and cause receptor dimerization and tyrosine kinase activation. The oncogenic activity of mutated RET has been demonstrated in cell culture and transgenic animals and represents an early oncogenic event in the development of MTC tumors (Kodama et al. 2005). There is an apparent correlation between genotype and phenotype in MTC, and RET mutations can be stratified into different risk levels (Machens et al. 2001).

Tyrosine kinases are crucial in the genesis of several malignant tumors. Activated tyrosine kinases stimulate cell proliferation, induce antiapoptotic effects, and promote metastasis formation and angiogenesis (Krause \& Van Etten 2005). There are several mechanisms for oncogenic activation of tyrosine kinases, e.g., overexpression of the tyrosine kinase due to gene amplification (ERBB2 in $25 \%$ of breast cancers; Slamon et al. 1989), point mutation increasing the activity of the tyrosine kinase (KIT in gastrointestinal stroma cell tumor (GIST); Rubin et al. 2001), and translocation leading to expression of a fusion oncoprotein with increased tyrosine kinase activity (BCRABL in chronic myeloid leukemia (CML); Warmuth et al. 1999). Tyrosine kinase inhibition is a novel and highly effective treatment modality that has already gained widespread clinical use for specific tumor diseases (Gschwind et al. 2004). In metastatic MTC with RET mutation, the tyrosine kinase is an attractive target for antitumor therapy (Leboulleux et al. 2004).

The aim of the present study was to establish a model of human MTC in nude mice. Here, we report the characterization of a human MTC in nude mice and demonstrate rapid tumor regression after treatment with RET tyrosine kinase inhibitor. Our findings support earlier evidence that tyrosine kinase inhibition may be an effective therapy in patients with advanced MTC (Pützer \& Drosten 2004).

\section{Material and methods}

\section{Case report}

A 79-year-old man with no family history of thyroid tumors presented with dysphagia and a cervical mass that originated from a large tumor in the left thyroid lobe, also invading the contralateral lobe. Numerous lymph node metastases were present in the central and the lateral neck compartments as well as in the mediastinum, but no distant metastases were found. Calcitonin levels were markedly elevated to $1030 \mathrm{ng} / \mathrm{l}$ (reference value $<20 \mathrm{ng} / \mathrm{l}$ ) and carcinoembryonic antigen (CEA) was elevated to $47 \mu \mathrm{g} / \mathrm{l}$ (reference value $<5 \mu \mathrm{g} / \mathrm{l})$. An attempt at radical surgery was performed with total thyroidectomy and cervical lymph node dissection. Histopathological analysis revealed MTC with multicentric growth in both thyroid lobes and regional lymph node metastases. Immunocytochemical analysis confirmed the diagnosis of MTC with very high proliferation index for this tumor type (Tisell et al. 1997, Ki67 positive in $28 \%$ of tumor cells; Table 2).

\section{Establishment and propagation of tumor in nude mice}

Tumor tissue from the patient was successfully transplanted to nude mice and the tumor cells in nude mice were designated GOT2 cells. The animal experiments were approved by the Ethical Committee for Animal Research at Göteborg University.

Briefly, 4- to 5-week-old BALB/cABom-nude female mice (Bomholtgaard, Ry, Denmark) were housed in cages with filtered air and fed and watered ad libitum. Two pieces of tumor tissue $(1 \times 1 \times 2 \mathrm{~mm}$ each) from a cervical lymph node metastasis obtained at surgery were transplanted subcutaneously between the scapulae of each of 22 mice via a small incision, under anesthesia with $2.5 \%$ tribromoethanol intraperitoneally (Avertin). Gross tumor was developed in only one of the 22 xenotransplanted mice after 3 months. Tumor tissue from this mouse was propagated by renewed transplantation of two pieces of tumor tissue $(1 \times 1 \times 2 \mathrm{~mm})$ to each of 25 animals. In this second generation, the take rate was $40 \%$. GOT2 cells grew slowly and the time from transplantation to visible tumor was about 3 months. Thus, experiments were performed 4-6 months after transplantation. The experimental model has been maintained by serial transplantations, as described above, over more than 5 years and 10 tumor generations. Tumor size in nude mice was monitored regularly with gauge blocks (longest diameter and one or two perpendicular diameters). Tumor volumes were calculated by assuming that the tumors were spheroid $\left(V=4 \pi r_{1} r_{2} r_{3} / 3\right)$.

\section{Assays of $\mathrm{CgA}$ and calcitonin}

At the end of the experiments, about $0.5 \mathrm{ml}$ plasma was collected from each animal and stored at $-70{ }^{\circ} \mathrm{C}$ until assayed. Plasma levels of human chromogranin A (CgA) were determined by competitive RIA using polyclonal antisera against fragments of human $\mathrm{CgA}$ (Öberg \& Stridsberg 2000). Calcitonin was measured with an automated immunoassay system (Nichols Advantage, Nichols Institute Diagnostics, San Juan Capistrano, CA, USA). 


\section{Immunocytochemistry}

Biopsies from tumors obtained at surgery (primary tumor) and from nude mice were fixed in $4 \%$ buffered formalin for $4-24 \mathrm{~h}$ and subsequently dehydrated and embedded in paraffin wax. Deparaffinized sections were subjected to antigen retrieval prior to incubation with primary antibodies overnight at $4{ }^{\circ} \mathrm{C}$ (Tables 1 and 2). Bound antibodies were visualized by indirect immunoperoxidase technique (EnVision and LSAB +, DAKO A/S, Glostrup, Denmark) with diaminobenzidine (DAB) as chromogen.

\section{Electron microscopy}

Tumors from transplanted nude mice were fixed in $2.5 \%$ glutaraldehyde in $0.1 \mathrm{M}$ sodium cacodylate buffer ( $\mathrm{pH} 7.2$ ) for $24-48 \mathrm{~h}$ and postfixed for $1 \mathrm{~h}$ in $1 \%$ osmium tetroxide. After dehydration, the specimens were embedded in epoxy resin. Ultrathin sections were placed on copper grids and contrasted with uranyl acetate and lead citrate before examination in a Philips CM12 electron microscope.

\section{Cell culture}

Tumor tissue from generations II, IV, and IX were prepared for cell culture as previously described (Nilsson et al. 1998). Tumor cells were maintained in culture for 2-4 weeks before fixation in $4 \%$ paraformaldehyde in phosphate buffered saline. Following preincubation with $5 \%$ nonfat milk, cultures were incubated overnight at $4{ }^{\circ} \mathrm{C}$ with primary antibodies (Table 1). Labeling was visualized using biotinylated secondary antibodies and then streptavidin-FITC. Cells were viewed and photographed using a Nikon Eclipse E800 fluorescence microscope.

\section{Western blot}

Proteins were extracted from tumor biopsies and cultured cells as previously described (Jakobsen et al. 2002). Briefly, tumor biopsies $(\sim 20 \mathrm{mg})$ and cell culture lysates $(\sim 20$ million cells) were homogenized, sonicated, and centrifuged. Proteins were electrophoresed, transferred to blotting membranes, and incubated with primary antibodies (Table 1) at $4{ }^{\circ} \mathrm{C}$ overnight. Alkaline phosphatase-conjugated secondary antibodies were applied after washing of the membranes and the immunoblots were visualized using, ECL film (Amersham Pharmacia Biotech, Buckhamshire, UK).

\section{Cytogenetic and spectral karyotype (SKY) analyses}

GOT2 cells were harvested as previously described (Nordkvist et al. 1994). Slides were subsequently G-banded and analyzed according to the guidelines of

Table 1 Primary antibodies used for immunocytochemistry and western blot

\begin{tabular}{llll}
\hline Antigen & Clone no. & Cat. no. & Source \\
\hline Calcitonin & & A0576 & DAKO \\
Serotonin & 5HT-H209 & M0758 & DAKO \\
Somatostatin & & A0566 & DAKO \\
Chromomogranin A & LK2H10 & MAB5268 & Chemicon \\
Synaptophysin & SY38 & M0776 & DAKO \\
SV2 & SP2/0 & SV2 & Developmental Studies Hybridoma Bank \\
VMAT1 & & SC-7718 & Santa Cruz \\
VMAT2 & & AB1767 & Chemicon \\
Tyrosine hydroxylase & $2 / 40 / 15$ & MAB5280 & Chemicon \\
Thyroglobulin & DAK-Tg6 & M0781 & DAKO \\
CEA & II-7 & M7072 & DAKO \\
Cytokeratin 8 & TS1 & NCL-CK8-TS1 & Novo Castra \\
Cytokeratin 18 & C51 & NCL-CK18-C51 & Novo Castra \\
ECAD & HECD-1 & $13-1700$ & Zymed \\
NCAM & 389 & SC-106 & Santa Cruz \\
TTF1 & $8 G 7 G 3 / 1$ & M3575 & DAKO \\
RET & & SC-167 & Santa Cruz \\
C-KIT (CD117) & A4502 & DAKO \\
Ki67 & MIB-1 & M7240 & DAKO \\
EGFR & EGFR.25 & NCL-EGFR-384 & Novo Castra \\
\hline
\end{tabular}

SV2, synaptic vesicle protein 2; VMAT, vesicular monoamine transporter; TH, tyrosine hydroxylase; CEA, carcinoembryonic antigen; ECAD, epithelial cadherin; NCAM, neural cell adhesion molecule; TTF1, thyroid transcription factor 1. DAKO A/S; Glostrup, Denmark; Chemicon International Inc., Temecula, CA, USA; Novo Castra Laboratories Ltd, Newcastle upon Tyne, UK; Santa Cruz Biotechnology Inc., Santa Cruz, CA, USA; Zymed Laboratories Inc., San Francisco, CA, USA; Developmental Studies Hybridoma Bank, lowa City, IA, USA. 
Table 2 Immunocytochemical characterization of GOT2 in nude mice and cell culture

\begin{tabular}{|c|c|c|c|c|}
\hline Primary tumor & Primary tumor & $\begin{array}{l}\text { GOT2 in nude mouse } \\
\text { generation } 2\end{array}$ & $\begin{array}{c}\text { GOT2 in nude mouse } \\
\text { generation } 4\end{array}$ & GOT2 cell culture \\
\hline Calcitonin & +++ & +++ & +++ & +++ \\
\hline Serotonin & - & - & - & + \\
\hline Somatostatin & + & - & - & - \\
\hline Chromogranin A & +++ & +++ & +++ & +++ \\
\hline Synaptophysin 38 & +++ & +++ & +++ & ++ \\
\hline SV2 & +++ & +++ & +++ & ++ \\
\hline VMAT1 & +++ & +++ & +++ & ++ \\
\hline VMAT2 & + & - & - & +++ \\
\hline Tyrosine hydroxylase & - & - & - & - \\
\hline Thyroglobulin & +++ & + & + & +++ \\
\hline CEA & +++ & +++ & +++ & + \\
\hline Cytokeratin 8 & +++ & + & + & +++ \\
\hline Cytokeratin 18 & +++ & +++ & +++ & +++ \\
\hline ECAD & +++ & +++ & +++ & +++ \\
\hline NCAM & +++ & +++ & +++ & +++ \\
\hline RET & +++ & +++ & +++ & +++ \\
\hline C-KIT (CD117) & - & - & - & + \\
\hline EGFR & - & - & - & - \\
\hline
\end{tabular}

Immunocytochemical staining was graded as:,$-<1 \% ;+, 1-24 \% ;++, 25-75 \% ;+++,>75 \%$ positive tumor cells respectively.

the International System for Human Cytogenetic Nomenclature (ISCN 1995). At least 15 metaphases were karyotyped.

SKY analysis was performed on slides aged 2-5 days. The conditions for pretreatment, hybridization, posthybridization washes, and detection were essentially as recommended by the manufacturer (Applied Spectral Imaging Ltd, Migdal Ha'Emek, Israel). Image acquisition was achieved with the SpectraCube system (ASI) mounted on a Zeiss Axioplan 2 imaging microscope equipped with a custom-designed optical filter cube (SKY-1; Chroma Technology, Brattleboro, VT, USA) and a $4^{\prime}, 6^{\prime}$-diamidino-2' ${ }^{\prime}$-phenylindole dihydrochloride (DAPI) filter (Schrock et al. 1996). Analysis of spectral images was performed using SkyView software (ASI) and 30 metaphases were analyzed in detail.

Fluorescent in situ hybridization (FISH) analysis was performed on metaphase chromosomes using an alpha satellite probe specific for chromosome 1 (Vysis Inc., Downers Grove, IL, USA). Chromosomes were counterstained with DAPI. Fluorescence signals were digitized, processed, and analyzed using the PowerGene FISH image analysis system (Applied Imaging International Ltd, Newcastle-Upon-Tyne, UK).

\section{Mutational analysis}

The RET gene was analyzed in the following tissues from the patient: normal (lymph node) and MTC tissues (primary tumor and lymph node metastases). The RET gene was also analyzed in tumor tissues from transplanted nude mice. Genomic DNA was extracted from frozen tissues using the Fast DNA kit (cat. no. 6540-400; Q-BIOgene, Carlsbad, CA, USA) and paraffin-embedded tissues using the QIAamp DNA mini kit (cat. no. 51304; Qiagen $\mathrm{GmbH}$, Hilden, Germany). Exons 10, 11, 14, and 16 of the RET gene were subjected to PCR amplification using the AmpliTaq Gold kit (cat. no. N808-0241; Applied Biosystems, Foster City, CA, USA). The following primers were used: exon 10 , forward primer: $5^{\prime}-\mathrm{GCA}$ GCA TTG TTG GGG GAC A-3'; reverse primer: $5^{\prime}$ GAC AGC AGC ACC GAG ACG AT-3'; exon 11, forward primer: $5^{\prime}$-CAT GAG GCC GAG CAT ACT CAG CC-3'; reverse primer: $5^{\prime}$-CAG ACA GCA GCG CCG AGA CGA TG-3'; exon 14, forward primer: $5^{\prime}$ TGG CTC CTG GAA GAC CCA AG-3'; reverse primer: $5^{\prime}$-TGG CTG GGT GCA GAG CCA TA-3'; exon 16, forward primer: $5^{\prime}$-GTT CTG TGC CCA GGA GTG TCT A-3'; reverse primer: $5^{\prime}$-GGT GTT TCT GTA ACC TCC ACC C-3'. Amplified exons were sequenced on an ABI PRISM 310 Genetic Analyzer (Applied Biosystems) using the Big Dye Terminator sequencing kit (cat. no. 433-7450; Applied Biosystems).

\section{Treatment of tumor-bearing nude mice with tyrosine kinase inhibitor ZD6474}

The effect of tyrosine kinase inhibitor ZD6474 on tumor growth was evaluated in tumor-bearing animals. ZD6474 inhibits vascular endothelium growth factor 2 (VEGFR-2), RET and epidermal growth factor receptor (EGFR) tyrosine kinases with an $\mathrm{IC}_{50}$ of 40 , 
150 , and $500 \mathrm{nM}$ respectively (Carlomagno et al. 2002b, Ryan \& Wedge 2005). ZD6474 (N-(4-bromo-2fluorophenyl)-6-methoxy-7-[(1-methylpiperidin-4yl)methoxy]quinazolin-4-amine) was provided by AstraZeneca and formulated as a 2.75 or $11 \mathrm{mg} / \mathrm{ml}$ suspension in $1 \%$ Polysorbat 80.

According to clinical phase I studies, doses of up to $300 \mathrm{mg} /$ day are well tolerated and are used in further clinical trials (Heymach 2005). Corresponding mouse plasma levels are achieved with doses of $25-100 \mathrm{mg} / \mathrm{kg}$ per day (Gustafson et al. 2006).

\section{Daily dosage experiments}

Sixteen animals (generation $\mathrm{V}$ ) were divided into three groups with similar distribution of tumor sizes: a) a high daily dose group receiving $100 \mathrm{mg} / \mathrm{kg}$ body weight $(n=6), \mathrm{b})$ a low daily dose group receiving $25 \mathrm{mg} / \mathrm{kg}$ body weight $(n=6)$, and c) a control group receiving vehicle alone $(n=5)$. The suspension was administered by oral gavage, 5 days a week for 5 weeks. Body weight and tumor size were measured 1-2 times per week. After 10 days of treatment, two animals in the treatment groups and one animal in the control group were killed for histological examination of tumor and normal tissues. In the control (day 4) and the high-dose groups (day 8), one animal per group was killed because of signs of illness (convulsions and extreme weight loss respectively).

\section{Weekly dosage experiments}

Seventeen animals (generation VIII) were divided into three groups with similar distribution of tumor sizes: a) a high weekly dose group receiving $250 \mathrm{mg} / \mathrm{kg}$ body weight $(n=6)$, b) a low weekly dose group receiving $100 \mathrm{mg} / \mathrm{kg}$ body weight $(n=6)$, and c) a control group receiving vehicle alone $(n=5)$. The suspension was administered by oral gavage, once a week for 4 weeks. Body weight and tumor size were measured 1-2 times per week. In the control group, one animal was killed because of large tumor burden after 16 days.

At the end of the experiments, the animals were carefully examined, and plasma and tumor tissues were collected for analysis of biochemical markers and morphological findings.

\section{Statistical analysis}

The correlations between GOT2 tumor weight and mouse plasma levels of $\mathrm{CgA}$ and calcitonin were tested by Spearman's rank correlation test. For analysis of the therapeutic effect of ZD6474 on GOT2 tumors in vivo, the tumor volumes in the treatment groups were compared with those in the control group using the Mann-Whitney test.

\section{Results}

\section{Propagation of GOT2 cells in nude mice}

GOT2 cells, xenografted to nude mice, were successfully propagated for 10 generations over more than 5 years. The transplantation take rate for the later generations was approximately $85 \%$. Since GOT2 cells have a slow growth rate, it took about 3-4 months after grafting before tumors could be observed. The estimated doubling time (volume) was about 3 weeks (Fig. 1).

\section{The neuroendocrine phenotype of GOT2 cells}

The growth pattern of GOT2 cells was very similar to that of the original tumor with tumor cells growing in nests and ribbons. The preserved phenotypic properties were further confirmed by immunohistochemistry (Table 2, and Fig 2) and by Western blot analysis (Fig. 3). As expected, there was strong labeling for calcitonin, $\mathrm{CEA}$, and $\mathrm{CgA}$ in both the primary tumor and GOT2 tumors, while tumor cells were negative for thyroglobulin and somatostatin. The neuroendocrine differentiation was well maintained with almost identical positive labeling for vesicular monoamine transporter 1 (VMAT1), synaptophysin (SY), and SV2. Ultrastructural analysis of transplanted tumors showed tumor cells with abundant cytoplasm containing numerous dense-core granules measuring 100$300 \mathrm{~nm}$ in diameter (Fig. 4). Plasma levels of both $\mathrm{CgA}$ and calcitonin were strongly correlated with MTC tumor burden $(P<0.001$; Fig. 5). The mouse plasma levels of $\mathrm{CgA}$ in this MTC model were about $25 \mathrm{nM} / \mathrm{g}$ tumor, which was in the same range as in our midgut carcinoid model with GOT1 cells xenografted to nude mice (Kölby et al. 2004).

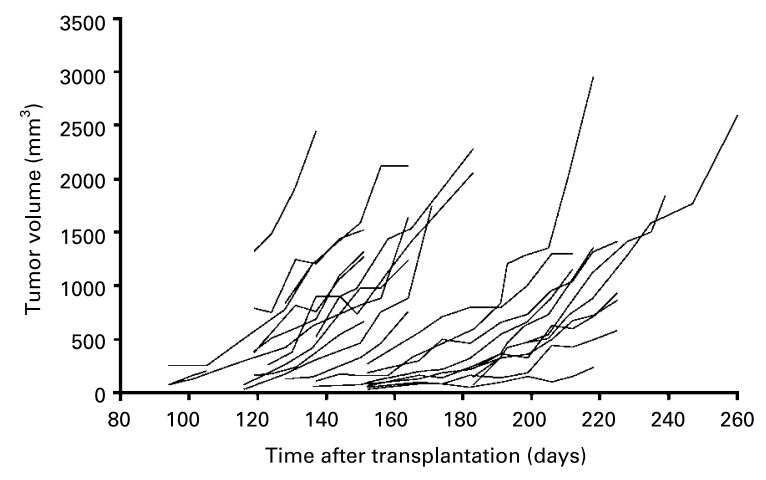

Figure 1 Volumes of individual GOT2 tumors in nude mice. The average doubling time in four different tumor generations is about 21 days. 


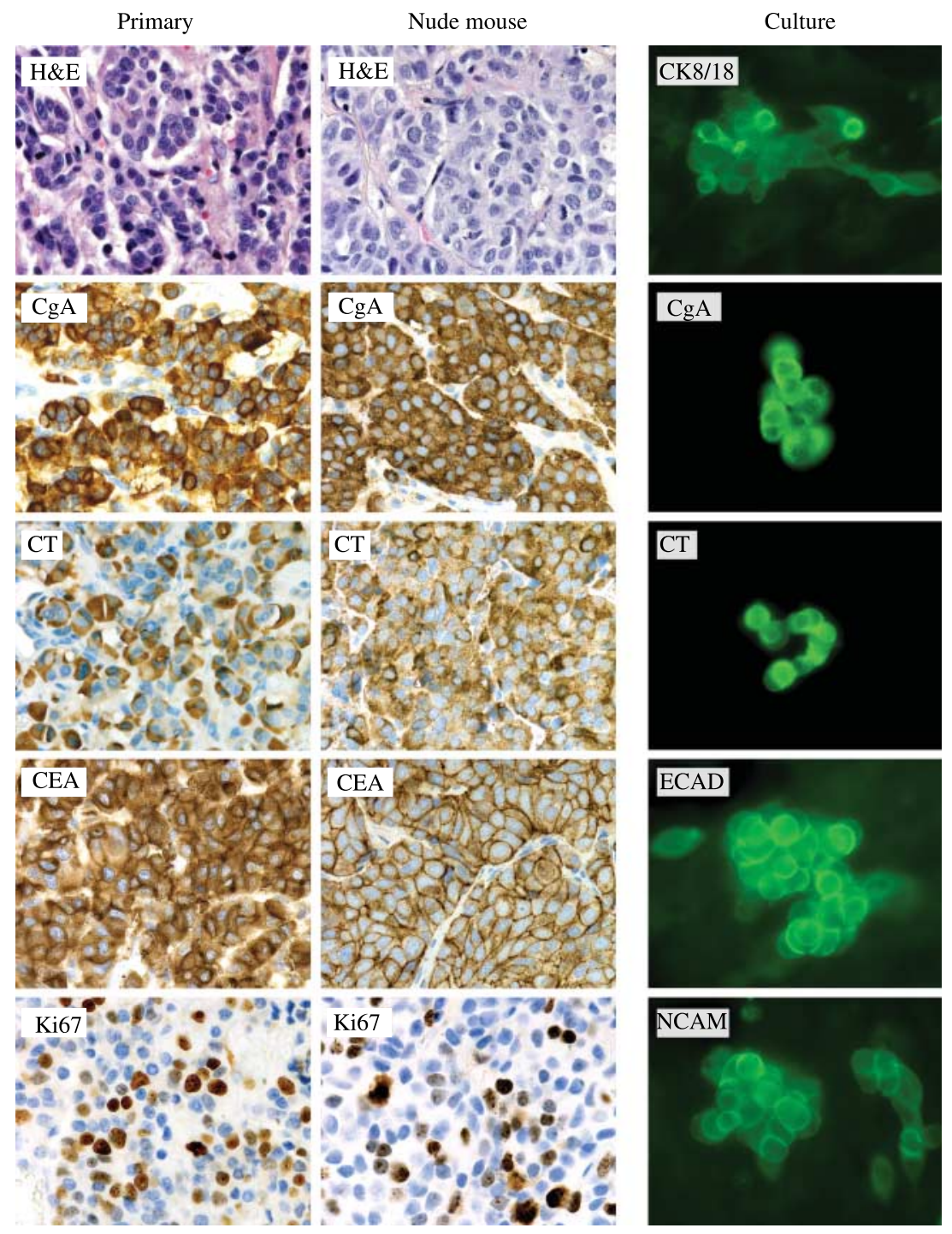

Figure 2 Morphological and immunocytochemical characterization of the primary MTC (Primary), GOT2 tumors grown in nude mice (Nude mice), and GOT2 cells in culture (Culture). Tumor cells in the primary tumor grow in nests and ribbons with moderate eosinophilic cytoplasm, hematoxylin and eosin (H\&E). The majority of tumor cells are positive for chromogranin $\mathrm{A}(\mathrm{CgA})$, calcitonin (CT) and carcinoembryonic antigen (CEA). The proliferation rate measured by Ki67 was relatively high ( $\sim 30 \%$ of nuclei positive). GOT2 cells grown in nude mice showed a similar growth pattern, immunophenotype and proliferation rate. Cultured GOT2 cells have immunocytochemical properties typical of MTC tumors. All tumor cells are positive for cytokerahn $8 / 18, \operatorname{chromogranin~A~(CgA),~}$ calcitonin (CT) ECAD and NCAM.

\section{Karyotypic characteristics of GOT2 cells}

Cytogenetic and SKY analyses revealed that the GOT2 cells had a complex karyotype with both structural and numerical abnormalities. The chromosome counts were in the triploid-hypotriploid region with a modal number of 69 (range 64-69). Detailed comparison of the G-banded karyotypes with the SKY karyotypes allowed us to resolve all marker chromosomes and map the breakpoints in all markers precisely. The GOT2 cells had the following karyotypes: $69, \mathrm{XX},-\mathrm{Y}$, $\operatorname{der}(1) \mathrm{t}(1 ; 11)(\mathrm{p} 36 ; \mathrm{q} 13.5) \times 2, \quad \operatorname{der}(1) \mathrm{t}(1 ; 5)(\mathrm{p} 13 ; \mathrm{p} 12-$ $13),+2,-3,-5,+6,+7,-9,+10, \mathrm{i}(10)(\mathrm{p} 10) \times 2$, $-13, \quad-15,+16, \quad \operatorname{del}(16)(\mathrm{q} 12-13) \times 2, \quad-17$, $\mathrm{i}(17)(\mathrm{q} 10) \times 2,+19,+20,-21,-22$ (Fig. 6). FISH analysis confirmed that the $\operatorname{der}(1) \mathrm{t}(1 ; 5)$ marker had a centromere derived from chromosome 1 . The karyotypic variation between individual cells was limited and consisted mainly of random losses of whole chromosomes. No cells with a normal karyotype were found. 

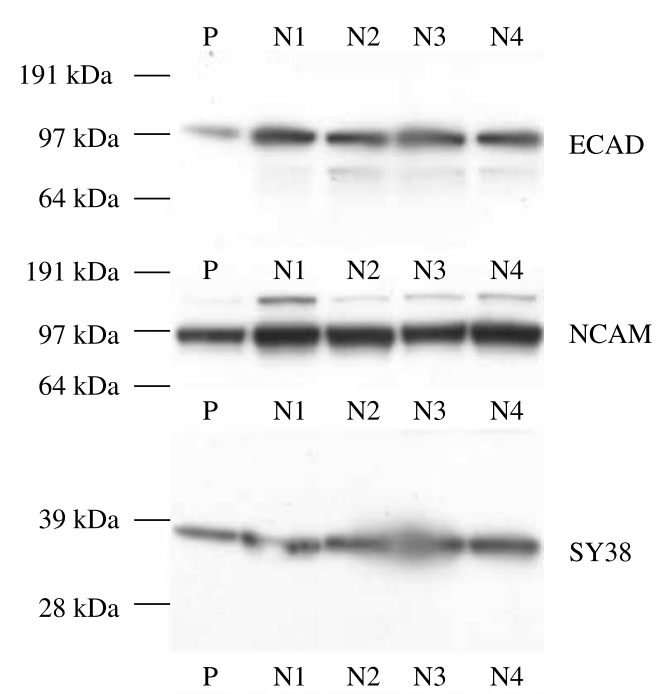

SY38

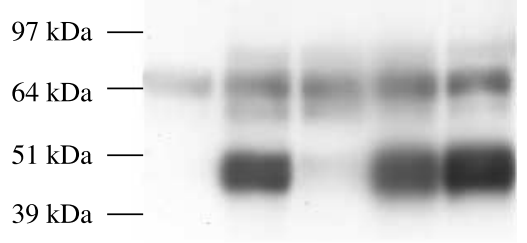

Figure 3 Western blot analysis of primary MTC (P) and GOT2 cells grown in nude mice (N1-N4). Primary tumor and transplanted tumors express the same set of adhesion molecules (ECAD, NCAM) and synaptic vesicle proteins synaptophysin (SY38), and synaptic vesicle protein 2 (SV2).

\section{RET mutations in GOT2 cells}

Nucleotide sequence analysis of the MTC tumor (primary and lymph node metastasis) from the patient revealed a homozygous RET mutation in exon 11 affecting codon 634, where cysteine had been substituted with arginine, C634R. This mutation was also found in the GOT2 tumors in which expression of $R E T$ was confirmed by western blot and immunofluorescence (Fig. 7). Mutational analysis of normal tissue
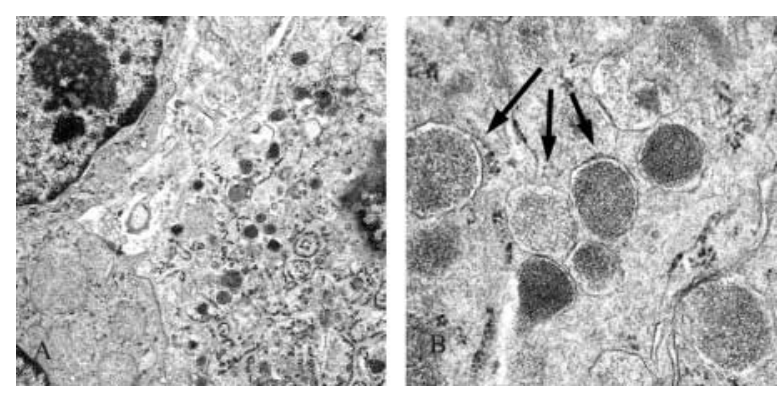

Figure 4 Ultrastructural characterization of GOT2 cells in nude mice. The cytoplasm of tumor cells contains numerous densecore granules, approximately $100-300 \mathrm{~nm}$ in diameter.

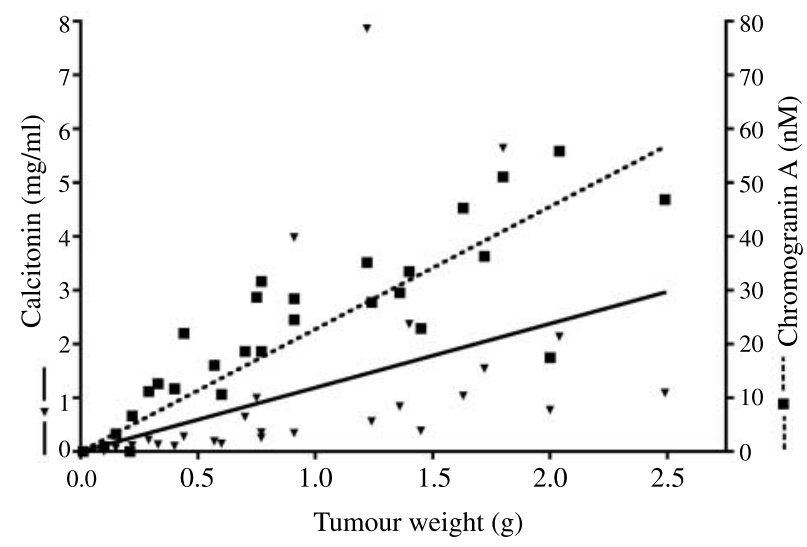

Figure 5 Plasma levels of calcitonin, chromogranin A and tumor volume in GOT2-bearing nude mice. A positive and significant $(<0.001)$ correlation between tumor markers and tumor volume was found.

from the patient (lymph node) demonstrated no RET mutation.

\section{Antitumor effect of ZD6474 on GOT2 xenografted to nude mice}

The antitumor effect of ZD6474 was tested in nude mice xenografted with GOT2 cells. With the daily (5 days/week) dose regimen, significant $(P<0.05)$ tumor regression was seen in the high daily dose group (100 mg/kg per day). Tumor volume was reduced to $30 \%$ of the initial tumor volume and to $11 \%$ of that of the control group and the low daily dose group $(25 \mathrm{mg} / \mathrm{kg}$ per day) after 5 weeks of treatment (Fig. 8). With the daily dose regimen, there was a decrease in animal weight by $1.5-2 \mathrm{~g}$ in both treatment groups and controls over the 5-week study period. At the end of experiments, plasma levels of $\mathrm{CgA}$ were significantly reduced $(P<0.05)$ in the high daily dose group dose relative to the control and the low daily dose groups.

To test whether a different dose regimen would have a less adverse effect on animal weight, a second set of experiments was performed in which GOT2-bearing mice were given peroral ZD6474 at two different doses, once a week. With this dose regimen, there was no significant reduction in animal weight in any group over the 4-week study period. In the high weekly dose group $(250 \mathrm{mg} / \mathrm{kg}$ per week), tumor volume was significantly reduced $(P<0.05)$ to $56 \%$ of the initial tumor volume and to $21 \%$ of that of the control group and $56 \%$ of that of the low weekly dose group after 4 weeks of treatment.

Microscopic evaluation of tumors in ZD6474treated animals revealed widespread areas of necrosis in the high daily dose and high weekly dose groups, 


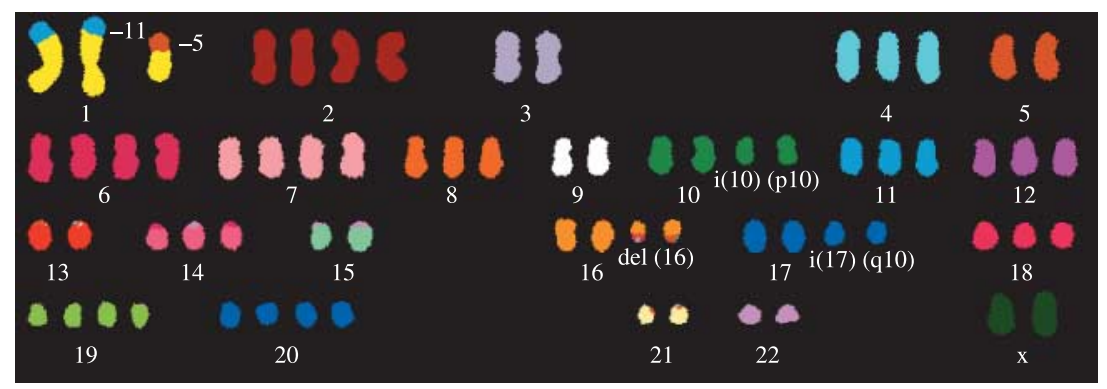

Figure 6 SKY karyotype of transplanted GOT2 tumor. Note the $\operatorname{der}(1) t(1 ; 11)$, $\operatorname{der}(1) t(1 ; 5), i(10)(p 10), \operatorname{del}(16)$, and $i(17)(q 10)$ markers.

while tumors in animals from the low daily dose group, the low weekly dose group and the control group contained no or only very limited areas of necrosis (Fig. 9).

\section{Discussion}

To be able to evaluate new treatment strategies, reliable models of human MTC are required. Here, we present a xenograft mouse model of human MTC, which has the characteristic morphology of MTC including expression of calcitonin, $\mathrm{CEA}, \mathrm{CgA}$, and
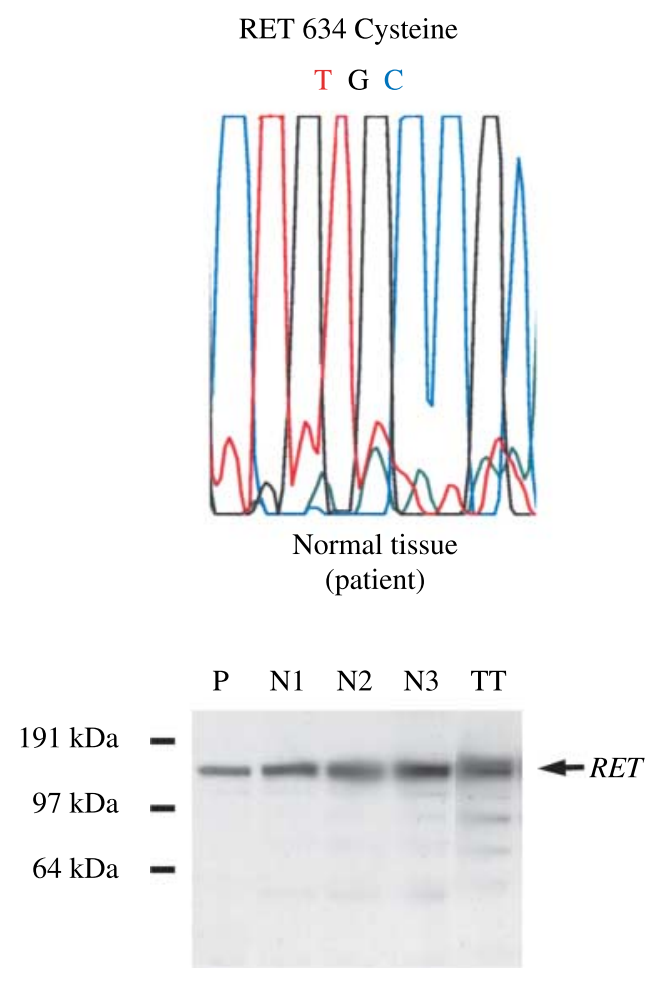

other neuroendocrine tumor markers. Like the parental tumor, the GOT2 cells have a mutated RET gene (C634R) the expression of which was confirmed by western blot and immunofluorescence.

Cytogenetic and SKY analyses of GOT2 cells showed that they were of human origin and had an abnormal, near-triploid karyotype. Most of the rearrangements were unbalanced, leading to losses and gains of specific chromosome segments. Using a combination of G-banding, FISH, and SKY, we were able to determine the composition of all markers. The karyotypic profile of GOT2 was consistent with a
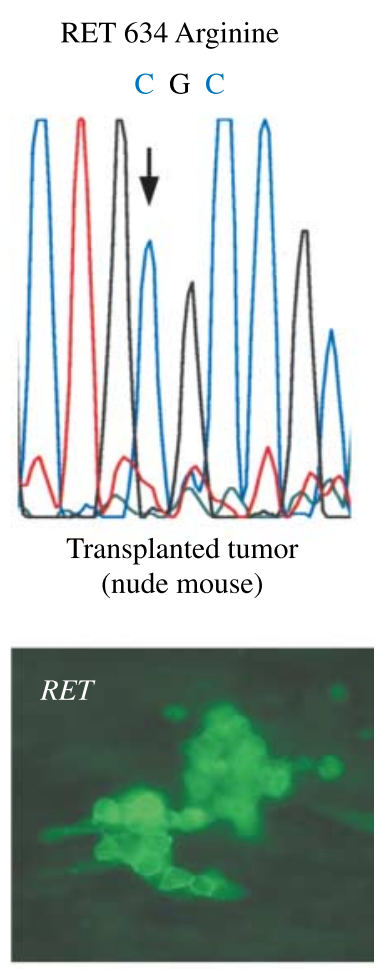

Figure 7 Mutational analysis and expression of $R E T$ in GOT2 tumors. Sequencing of the RET gene revealed a single point mutation at codon $634(T G C \rightarrow C G C)$, converting cysteine to arginine (C634R). Expression of RET protein in the primary MTC $(P)$ and in transplanted tumors (N1-N3) was demonstrated by western blot. Localization of RET protein to tumor cell membranes was shown in cultured tumor cells by immunofluorescence. 

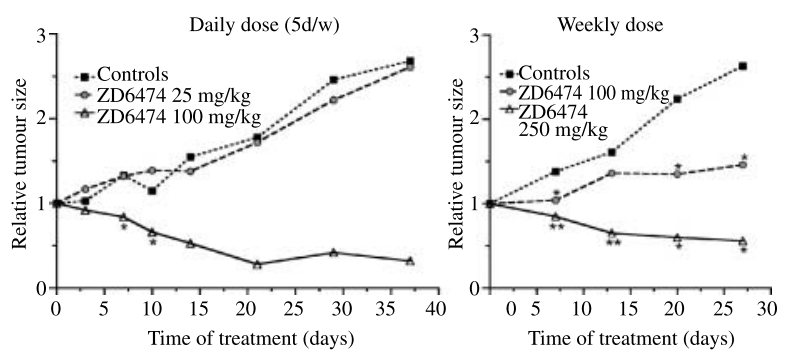

Figure 8 Antitumor effect of the tyrosine kinase inhibitor ZD6474 on GOT2 tumors in nude mice. With the daily dose regimen (left) significant tumor regression was seen in the high dose group. With the weeklydose regimen (right) significant tumor inhibition was seen in both the low- and the high-dose groups. Mean values of relative tumor volumes, for each tumor the volume at day 0 was set to $1 .{ }^{*} P<0.05$ vs controls. ${ }^{\star \star} P<0.01$ vs controls.

tumor in the late stage of progression. Recently, we became aware that a diagnostic cytogenetic analysis was performed on a needle biopsy from the patient at the time of diagnosis in March 2001. At that time, the tumor had a hypertriploid karyotype with the following marker chromosomes: $1 \mathrm{p}+(\mathrm{x} 2), 1 \mathrm{p}-(\mathrm{x} 2), 5 \mathrm{q}-$, $7 q+, i(10 p)(x 2), 15 q+$. Since no FISH or SKY analyses were performed, the exact chromosomal composition of these markers remained unknown. Of the original marker chromosomes, the $1 \mathrm{p}+, 1 \mathrm{p}-$, and the $\mathrm{i}(10 \mathrm{p})$ markers were still present in our analysis performed 1.5 years later. These abnormalities are likely to represent early cytogenetic events of possible pathogenetic importance. Our knowledge of chromosome abnormalities in MTC is very limited. There have only been a few reports on studies of cell lines mainly using conventional banding techniques (Pfragner et al. 1990, 1992, Cooley et al. 1995). To date, no recurrent abnormalities have been observed. Continued cytogenetic and molecular cytogenetic studies of MTC are therefore warranted. Mutational analysis of the primary MTC and GOT2 cells revealed a homozygous mutation in the RET gene (C634R), located in the long arm of chromosome 10. SKY analysis of GOT2 cells demonstrated two copies of the long arm of chromosome 10, indicating duplication of the mutated RET gene. Allelic imbalance of mutant and wild-type RET alleles with duplication of mutant RET has previously been demonstrated in MEN2-associated MTC (Koch et al. 2001).

The overall prognosis for patients with nonresectable MTC is still poor. However, the prognosis of individual MTC patients has been difficult to predict from tumor stage, tumor differentiation, ploidy, or biochemical markers. Recently, high Ki67 index was shown to correlate with shorter cause-specific postoperative survival (Tisell et al. 2003). Half of the MTC tumors can be localized scintigraphically due to expression of somatostatin receptors. Visualized tumors grew more rapidly and aggressively than nonvisualized tumors, indicating that octreotide scintigraphy may be another prognostic tool (Tisell et al. 1997). The GOT2 tumors had only low expression of somatostatin receptors and are therefore not well suited for treatment by somatostatin receptor-mediated radiotherapy. During the last few years, a new generation of antitumor agents has been developed known as molecular-targeted drugs. The first clinically available molecular-targeted drug was imatinib, which inhibits BCR-ABL, plateletderived growth factor receptor alpha (PDGFRA) and KIT tyrosine kinases, and has become the gold standard therapy for CML and GIST (Druker 2002).

Imatinib has been shown to inhibit the growth of MTCs (TT cells) in vitro (Cohen et al. 2002) but with doses that are clinically unattainable (Plaza Menacho et al. 2004, Skinner et al. 2003). Imatinib has also been shown to retard the growth of TT tumors in nude mice (Ezzat et al. 2005). Several RET tyrosine kinase
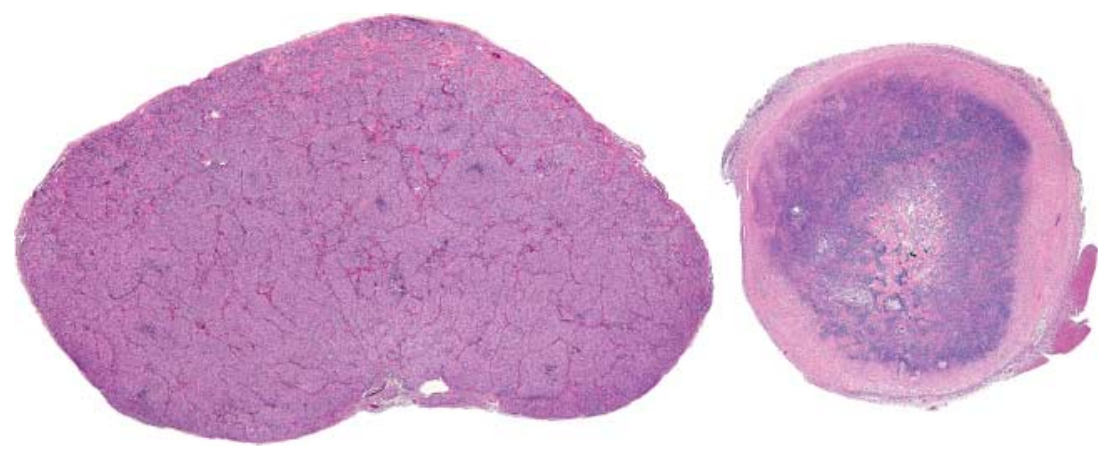

Figure 9 Antitumor effect of the tyrosine kinase inhibitor ZD6474 on GOT2 tumors in nude mice. The tumors in the control (left) and the ZD6474 treated (100 mg/kg per day) animal (right) were initially of equal size. After 5 weeks of treatment, the whole tumor in the control animal was viable, while the tumor in the ZD6474 treated animal showed widespread necrosis and a considerable reduction in size. 
inhibitors, e.g., PP1, CEP-751, RPI-1, and BAY 439006 have been shown to exert a growth-retarding effect on tumor cells harboring RET/PTC or RET/ MEN2A oncogenes (Carlomagno et al. 2002a, 2006, Cuccuru et al. 2004; Strock et al. 2003). ZD6474, an orally bioavailable small molecule inhibitor of VEGFR and EGFR tyrosine kinases, have been shown to inhibit the growth of tumor cell lines in vitro and in vivo (Ryan \& Wedge 2005). ZD6474 also inhibits the RET tyrosine kinase and has been shown to have antitumor effects in mice xenografted with human papillary thyroid cancer cell lines with oncogenic RET/PTC rearrangements or 3T3 cells carrying activated RET/ MEN2A tyrosine kinase (Carlomagno et al. 2002b). Several clinical phase I/II trials with ZD6474 have been published demonstrating objective response in non-small cell lung cancer (Heymach 2005). In a current phase II trial, which is being conducted in patients with metastatic hereditary MTC, early results of ZD6474 have shown response in 30\% of patients (Wells et al. 2006). Here, we demonstrate for the first time that ZD6474 effectively inhibits RET driven tumor growth in MTC. In our model, ZD6474 was shown to have a strong antitumor effect with widespread tumor cell necrosis and rapid tumor regression. The doses of ZD6474 used in this study have previously been used in mouse xenotransplant studies with minor adverse effects (Wedge et al. 2002, McCarty et al. 2004). These doses have been shown to result in plasma levels in mice (Gustafson et al. 2006) similar to those achieved in man in phase I trials (Holden et al. 2005). In conclusion, our studies show that this new MTC model, the GOT2, is well suited to study novel antitumor agents and is supportive of RET inhibition as an effective strategy for the treatment of advanced MTC.

\section{Acknowledgements}

The expert technical assistance of Ellinor Andersson, Gülay Altiparmak, Malin Berntsson, Ann-Christin Illerskog-Lindström, Siw Tuneberg and Ann Wikström is gratefully acknowledged. We thank Dr Anderson Ryan (AstraZeneca) for kindly providing ZD6474. The authors declare that there is no conflict of interest that would prejudice the impartiality of this scientific work.

\section{Funding}

Supported by grants from the Swedish Cancer Society, the Swedish MRC (5220), the I B and A Lundberg Research Foundation, the Assar Gabrielsson Foundation, the Swedish Society of Medicine, the Swedish
Society for Medical Research, the Göteborg Medical Society, the King Gustav V Jubilee Clinic Cancer Fund, Sahlgrenska University Hospital Research Funds, the Gunvor and Josef Anér Foundation, the Axel Linders Foundation, the Gunnar, Arvid and Elisabet Nilssons Foundation and the Serena Ehrenströms Foundation.

\section{References}

Brauckhoff M, Lorenz K, Ukkat J, Brauckhoff K, Gimm O \& Dralle H 2004 Medullary thyroid carcinoma. Scandinavian Journal of Surgery 93 249-260.

Carlomagno F, Vitagliano D, Guida T, Napolitano M, Vecchio G, Fusco A, Gazit A, Levitzki A \& Santoro M $2002 a$ The kinase inhibitor PP1 blocks tumorigenesis induced by RET oncogenes. Cancer Research 62 1077-1082.

Carlomagno F, Vitagliano D, Guida T, Ciardiello F, Tortora G, Vecchio G, Ryan AJ, Fontanini G, Fusco A \& Santoro M 2002b ZD6474, an orally available inhibitor of KDR tyrosine kinase activity, efficiently blocks oncogenic RET kinases. Cancer Research 62 7284-7290.

Carlomagno F, Anaganti S, Guida T, Salvatore G, Troncone G, Wilhelm SM \& Santoro M 2006 BAY 43-9006 inhibition of oncogenic RET mutants. Journal of the National Cancer Institute 98 326-334.

Cohen MS, Hussain HB \& Moley JF 2002 Inhibition of medullary thyroid carcinoma cell proliferation and RET phosphorylation by tyrosine kinase inhibitors. Surgery 132 960-966.

Cooley LD, Elder FF, Knuth A \& Gagel RF 1995 Cytogenetic characterization of three human and three rat medullary thyroid carcinoma cell lines. Cancer Genetics and Cytogenetics 80 138-149.

Cuccuru G, Lanzi C, Cassinelli G, Pratesi G, Tortoreto M, Petrangolini G, Seregni E, Martinetti A, Laccabue D, Zanchi C et al. 2004 Cellular effects and antitumor activity of RET inhibitor RPI-1 on MEN2A-associated medullary thyroid carcinoma. Journal of the National Cancer Institute 96 1006-1014.

Druker BJ 2002 Perspectives on the development of a molecularly targeted agent. Cancer Cell 1 31-36.

Eng C 1999 RET proto-oncogene in the development of human cancer. Journal of Clinical Oncology 17 380-393.

Ezzat S, Huang P, Dackiw A \& Asa SL 2005 Dual inhibition of RET and FGFR4 restrains medullary thyroid cancer cell growth. Clinical Cancer Research 11 1336-1341.

Gschwind A, Fischer OM \& Ullrich A 2004 The discovery of receptor tyrosine kinases: targets for cancer therapy. Nature Reviews. Cancer 4 361-370.

Gustafson DL, Bradshaw-Pierce EL, Merz AL \& Zirrolli JA 2006 Tissue distribution and metabolism of the tyrosine 
kinase inhibitor ZD6474 (Zactima) in tumor bearing nude mice following oral dosing. Journal of Pharmacology and Experimental Therapeutics 318 872-880.

Heymach JV 2005 ZD6474-clinical experience to date. British Journal of Cancer 92 14-20.

Holden SN, Eckhardt SG, Basser R, de Boer R, Rischin D, Green M, Rosenthal MA, Wheeler C, Barge A \& Hurwitz HI 2005 Clinical evaluation of ZD6474, an orally active inhibitor of VEGF and EGF receptor signaling, in patients with solid, malignant tumors. Annals of Oncology 16 1391-1397.

ISCN 1995 In An International System for Human Cytogenetic Nomenclature, Ed F Mitelman. Basel: S. Karger.

Jakobsen AM, Ahlman H, Wängberg B, Kölby L, Bengtsson M \& Nilsson O 2002 Expression of synaptic vesicle protein 2 (SV2) in neuroendocrine tumours of the gastrointestinal tract and pancreas. Journal of Pathology 196 44-50.

Juweid M, Sharkey RM, Behr T, Swayne LC, Herskovic T, Pereira M, Rubin AD, Hanley D, Dunn R, Siegel J et al. 1996 Radioimmunotherapy of medullary thyroid cancer with iodine-131-labeled anti-CEA antibodies. Journal of Nuclear Medicine 37 905-911.

Koch CA, Huang SC, Moley JF, Azumi N, Chrousos GP, Gagel RF, Zhuang Z, Pacak K \& Vortmeyer AO 2001 Allelic imbalance of the mutant and wild-type RET allele in MEN 2A-associated medullary thyroid carcinoma. Oncogene 20 7809-7811.

Kodama Y, Asai N, Kawai K, Jijiwa M, Murakumo Y, Ichihara M \& Takahashi M 2005 The RET protooncogene: a molecular therapeutic target in thyroid cancer. Cancer Science 96 143-148.

Kölby L, Bernhardt P, Swärd C, Johanson V, Ahlman H, Forssell-Aronsson E, Stridsberg M, Wängberg B \& Nilsson O 2004 Chromogranin A as a determinant of midgut carcinoid tumour volume. Regulatory Peptides 120 269-273.

Krause DS \& Van Etten RA 2005 Tyrosine kinases as targets for cancer therapy. New England Journal of Medicine 353 172-187.

Leboulleux S, Baudin E, Travagli JP \& Schlumberger M 2004 Medullary thyroid carcinoma. Clinical Endocrinology 61 299-310.

Machens A, Gimm O, Hinze R, Hoppner W, Boehm BO \& Dralle H 2001 Genotype-phenotype correlations in hereditary medullary thyroid carcinoma: oncological features and biochemical properties. Journal of Clinical Endocrinology and Metabolism 86 1104-1109.

McCarty MF, Wey J, Stoeltzing O, Liu W, Fan F, Bucana C, Mansfield PF, Ryan AJ \& Ellis LM 2004 ZD6474, a vascular endothelial growth factor receptor tyrosine kinase inhibitor with additional activity against epidermal growth factor receptor tyrosine kinase, inhibits orthotopic growth and angiogenesis of gastric cancer. Molecular Cancer Therapeutics 3 1041-1048.
Moley JF, Debenedetti MK, Dilley WG, Tisell LE \& Wells SA 1998 Surgical management of patients with persistent or recurrent medullary thyroid cancer. Journal of Internal Medicine 243 521-526.

Nilsson O, Kölby L, Wängberg B, Wigander A, Billig H, William-Olsson L, Fjälling M, Forssell-Aronsson E \& Ahlman H 1998 Comparative studies on the expression of somatostatin receptor subtypes, outcome of octreotide scintigraphy and response to octreotide treatment in patients with carcinoid tumours. British Journal of Cancer 77 632-637.

Nordkvist A, Mark J, Gustafsson H, Bang G \& Stenman G 1994 Non-random chromosome rearrangements in adenoid cystic carcinoma of the salivary glands. Genes, Chromosomes and Cancer 10 115-121.

Öberg K \& Stridsberg M 2000 Chromogranins as diagnostic and prognostic markers in neuroendocrine tumours. Advances in Experimental Medicine and Biology 482 329-337.

Pfragner R, Hofler H, Behmel A, Ingolic E \& Walser V 1990 Establishment and characterization of continuous cell line MTC-SK derived from a human medullary thyroid carcinoma. Cancer Research 50 4160-4166.

Pfragner R, Wirnsberger G, Behmel A, Niederle B, Langle F, Roka R, Mandl A, Purstner P, Auner J \& Tatzber F 1992 Biologic and cytogenetic characterization of three human medullary thyroid carcinomas in culture. Henry Ford Hospital Medical Journal 40 299-302.

Plaza Menacho I, de Groot JW, Links T, Plukker J, Eggen BJ \& Hofstra R 2004 Re: inhibition of medullary thyroid carcinoma (MTC) cell proliferation and RET phosphorylation by tyrosine kinase inhibitors. Surgery 135 240-241.

Pützer BM \& Drosten M 2004 The RET proto-oncogene: a potential target for molecular cancer therapy. Trends in Molecular Medicine 10 351-357.

Rubin BP, Singer S, Tsao C, Duensing A, Lux ML, Ruiz R, Hibbard MK, Chen CJ, Xiao S, Tuveson DA et al. 2001 KIT activation is a ubiquitous feature of gastrointestinal stromal tumors. Cancer Research 61 8118-8121.

Ryan AJ \& Wedge SR 2005 ZD6474-a novel inhibitor of VEGFR and EGFR tyrosine kinase activity. British Journal of Cancer 92 S6-13.

Samaan NA, Schultz PN, Hickey RC, Goepfert H, Haynie TP, Johnston DA \& Ordonez NG 1992 The results of various modalities of treatment of well differentiated thyroid carcinomas: a retrospective review of 1599 patients. Journal of Clinical Endocrinology and Metabolism 75 714-720.

Schlumberger M, Abdelmoumene N, Delisle MJ \& Couette JE 1995 Treatment of advanced medullary thyroid cancer with an alternating combination of 5 FU-streptozocin and 5 FU-dacarbazine. The Groupe d'Etude des Tumeurs Calcitonine (GETC). British Journal of Cancer 71 363-365. 
Schrock E, du Manoir S, Veldman T, Schoell B, Wienberg J, Ferguson-Smith MA, Ning Y, Ledbetter DH, Bar-Am I, Soenksen D et al. 1996 Multicolor spectral karyotyping of human chromosomes. Science 273 494-497.

Skinner MA, Safford SD \& Freemerman AJ 2003 RET tyrosine kinase and medullary thyroid cells are unaffected by clinical doses of STI571. Anticancer Research $\mathbf{2 3}$ 3601-3606.

Slamon DJ, Godolphin W, Jones LA, Holt JA, Wong SG, Keith DE, Levin WJ, Stuart SG, Udove J, Ullrich A et al. 1989 Studies of the HER-2/neu proto-oncogene in human breast and ovarian cancer. Science 244 707-712.

Strock CJ, Park JI, Rosen M, Dionne C, Ruggeri B, Jones-Bolin S, Denmeade SR, Ball DW \& Nelkin BD 2003 CEP-701 and CEP-751 inhibit constitutively activated RET tyrosine kinase activity and block medullary thyroid carcinoma cell growth. Cancer Research 63 5559-5563.

Tisell LE, Ahlman H, Wängberg B, Hansson G, Mölne J, Nilsson O, Lindstedt G, Fjälling M \& ForssellAronsson E 1997 Somatostatin receptor scintigraphy in medullary thyroid carcinoma. British Journal of Surgery 84 543-547.
Tisell LE, Odén A, Muth A, Altiparmak G, Mölne J, Ahlman H \& Nilsson O 2003 The Ki67 index a prognostic marker in medullary thyroid carcinoma. British Journal of Cancer 89 2093-2097.

Warmuth M, Danhauser-Riedl S \& Hallek M 1999 Molecular pathogenesis of chronic myeloid leukemia: implications for new therapeutic strategies. Annals of Hematology 78 49-64.

Wedge SR, Ogilvie DJ, Dukes M, Kendrew J, Chester R, Jackson JA, Boffey SJ, Valentine PJ, Curwen JO, Musgrove HL et al. 2002 ZD6474 inhibits vascular endothelial growth factor signaling, angiogenesis, and tumor growth following oral administration. Cancer Research 62 4645-4655.

Wells S, You YN, Lakhani V, Hou J, Langmuir P, Headley D, Skinner M, Morse M, Burch W \& Schlumberger M 2006 A phase II trial of ZD6474 in patients with hereditary metastatic medullary thyroid cancer. Journal of Clinical Oncology 245533.

Wu LT, Averbuch SD, Ball DW, de Bustros A, Baylin SB \& McGuire WP III 1994 Treatment of advanced medullary thyroid carcinoma with a combination of cyclophosphamide, vincristine, and dacarbazine. Cancer 73 432-436. 